\title{
Effect of Tribulus terrestris, ginger, saffron, and Cinnamomum on menopausal symptoms: a randomised, placebo-controlled clinical trial
}

\author{
Simin Taavoni ${ }^{1,2}$, Neda Nazem Ekbatani ${ }^{3}$, Hamid Haghani ${ }^{4}$ \\ ${ }^{1}$ Research Institute for Islamic \& Complementary Medicine, Iran University of Medical Sciences, (RICM, TUMS), Tehran, Islamic Republic \\ of Iran \\ ${ }^{2}$ School of Medicine, Medical Education Group (PhD Student in Medical Education), Tehran University of Medical Sciences, Tehran, \\ Islamic Republic of Iran \\ ${ }^{3}$ Nursing and Midwifery Faculty (PhD Student in Reproductive Health), Tehran University of Medical Sciences, Tehran, Islamic Republic \\ of Iran \\ ${ }^{4}$ Statistics Department, School of Management and Medical Information \& Health Sciences, Iran University of Medical Sciences, \\ Tehran, Islamic Republic of Iran
}

\begin{abstract}
Menopausal symptoms experienced by women vary widely, and while many women transition through menopause with manageable symptoms, others experience severe symptoms, which may impair their quality of life. The purpose of this study was to determine the effect of Tribulus terrestris, ginger, saffron, and Cinnamomum on menopausal symptoms. A randomised, triple-blind, controlled trial design was used for this study. The participants were 80 postmenopausal women aged 50-60 years. A demographic data form and the Menopause Rating Scale were used to collect data. The women were randomly divided into two groups, each of which received either an Aphrodit capsule or a placebo twice a day for four weeks. The two bottles looked exactly the same, so that the investigator and the participants were not aware of the contents of the bottles. Each Aphrodit capsule contained $40 \mathrm{mg}$ of Tribulus terrestris, $12.27 \mathrm{mg}$ of Zingiber officinale, $3 \mathrm{mg}$ of Crocus sativus extract, and $11 \mathrm{mg}$ of Cinnamomum zeylanicum, while the placebo capsules contained $50 \mathrm{mg}$ of starch. Descriptive and inferential statistics were used to analyse the data. A statistically significant change was reported in the menopausal symptoms of the intervention group compared with the placebo group. The results of the study demonstrate that the Aphrodit capsule was effective in reducing menopausal symptoms.
\end{abstract}

Key words: Aphrodit, menopausal symptoms, menopause rating scale, clinical trial.

\section{Introduction}

Menopause is a natural phase of life, but it can bring about physical problems for women. Menopause is defined as the time following the final menstrual period, and it is usually confirmed when a woman has missed her periods for 12 consecutive months in the absence of other obvious causes [1]. Menopausal syndrome includes a variety of symptoms, such as fatigue, headache, nervousness, loss of libido, insomnia, depression, irritability, palpitations, and joint and muscle pain [2, 3].

Menopause is often accompanied by physical symptoms, such as hot flushes, and emotional changes, such as mood swings. There is also an increased tendency towards obesity [4]. Psychological symptoms include mood changes, irritability, anxiety, nervous tension, difficulty concentrating, and depression. These symptoms have been linked to hormonal changes and can impair overall quality of life for a substantial number of women $[5,6]$. Several large, longitudinal studies have demonstrated an increased risk of depression or depressive symptoms during the menopausal transition [5-7]; $80 \%$ of women in pre-menopause or early menopause complain of these symptoms [8]. Approximately $61 \%$ of postmenopausal women have sleep problems, which can lead to other problems, such as daytime drowsiness [9]. Hot flushes (which affect $75-85 \%$ of postmenopausal women) and night sweats can affect sleep quality as well [10].

A wide variety of pharmacological and non-pharmacological methods of addressing symptoms at this stage of life are available $[11,12]$. One of the pharmacological methods is hormone therapy $[6,13]$; in the past, women were encouraged to use hormone replacement therapy (HRT) to relieve menopausal symptoms [14]. Although there is substantial evidence of the advantages of HRT 
[15-17], due to widespread anxiety over its safety, and after the publication of the Women's Health Initiative and the Million Women Study, there has been growing interest in complementary and alternative medicines $[16,18$, 19]. Complementary and alternative medical therapies might be useful for managing symptoms in older adults [20]. Aphrodit is a herbal supplement consisting of several plants, such as ginger, saffron, cinnamon, and Tribulus terrestris; each of the compounds has a special therapeutic effect. Mazora et al. (2010) introduced Tribulus terrestris fruit as a herbal supplement effective in sexual performance in women [21]. In addition, a number of recent experimental studies and clinical trials have indicated that saffron is effective in the treatment of mild to moderate depression [22]. According to an article published in "Social Science \& Medicine", ginger has been used to treat the symptoms of hot flushes and night sweats associated with menopause [23].

In contrast, in a study by Huntley and Ernst (2003) investigating the effects of black cohosh, red clover, kava, dong quai, and other herbal supplements on hot flushes in 45-65-year-old women, the results showed that they were of no benefit [24]. Nonetheless, it was confirmed that Aphrodit reduced sexual dysfunction in menopause [25], and Low in a study conducted in the USA, observed that taking saffron supplements resulted in improvements in hot flushes and other menopausal symptoms [26].

Because studies regarding the effects of Aphrodit on sexual performance have reported controversial findings, this study examined the effect of oral Aphrodit capsules on menopausal symptoms, in order to contribute to the strategies available for improving quality of life in postmenopausal women and to increase the health levels of the family and the community.

\section{Material and methods}

In this randomised, controlled, triple-blind study, participant recruitment and data collection were conducted between August 2013 and July 2014. A sample of menopausal women experiencing self-reported menopause symptoms was recruited for the study. The inclusion criteria were as follows: generally healthy females aged 50-60 years, menopausal for at least one year, not using HRT, and no medical or psychiatric conditions. Any participant consuming other drugs during the study was excluded. The other exclusion criteria included consuming Aphrodit capsules for less than three weeks and any serious medical conditions.

Two surveys were used in this study. The first study was a demographics collection questionnaire that included ten items: age, age at onset of menopause, marital status, education status, occupational status, economic status, age difference between the subject and her partner, number of pregnancies, number of children, and family size. The second study was the Menopause Rating Scale (MRS) questionnaire. The scale is designed and standardised to assess the occurrence and severity of the symptoms/complaints of postmenopausal women. The MRS is composed of 11 items that assess menopausal symptoms, including depressive mood, irritability, anxiety, hot flushes, heart discomfort, sleeping problems, muscle and joint problems, sexual problems, bladder problems, and dryness of the vagina. Each of the 11 symptoms contained in the scale is given a score of 0 (no complaints) to 4 (severe symptoms), depending on the severity of the complaint. For a particular individual, the total MRS score is the sum of the scores obtained for each symptom [24]. Heinemann et al. (2003) have published translations of the MRS in various languages, and the Persian version has been used previously in various studies in Iran [25, 27].

After detailed explanations of the procedure and the general objective of the study were provided to the participants, they gave informed consent and were randomly assigned to the Aphrodit or placebo group (A and $B$ bottles, respectively). As the study was triple-blind, only the pharmacist knew the identity of each type of capsule, and because the participants and investigator were blind to the treatment, the statistician was also blind until the analysis was completed. The two bottles appeared completely the same, so that the investigator and the participants were not aware of the contents of the bottles. Each Aphrodit capsule contained $40 \mathrm{mg}$ of Tribulus terrestris, $12.27 \mathrm{mg}$ of Zingiber officinale, $3 \mathrm{mg}$ of Crocus sativus extract, and $11 \mathrm{mg}$ of Cinnamomum zeylanicum, while the placebo capsules contained $50 \mathrm{mg}$ of starch. Both groups took one of their respective capsules twice daily for four weeks. Aphrodit is a herbal supplement produced by the Goldaru Company in Tehran. All of the participants were followed up weekly by phone, and they were asked to fill out the MRS again after completing the intervention.

Sample size was calculated based on $80 \%$ power and $5 \%$ type 1 error, and it was determined that 40 subjects were needed for each group. The subjects were involved in the study until the end of week 4. During the follow-up visits, the participants were informed of their actual treatment. Of the 80 participants who were enrolled in this study, 63 women successfully followed and completed the study protocol (21.2\% were excluded). This reduction in sample size was attributed to the following reasons: diagnosis of diabetes $(n=4)$, diagnosis of hypertension $(n=3)$, use of aspirin $(n=4)$, and irregular consumption of the capsules $(n=6)$. After one month all of the participants visited their healthcare centres again and completed the MRS assessment. The scores of the two groups before and after the intervention were measured, compared, and analysed. The results were analysed using paired and independent $t$ tests. A level of 0.05 was considered significant in the tests. All analyses were performed using SPSS 
software. All ethical considerations were followed, and the study was approved by the Research Chancellor of Iran University of Medical Sciences.

\section{Results}

All 63 participants completed the MRS for the second time following the intervention. To assess the equivalence of the two groups, personal characteristics were analysed. No significant differences were noted in the personal characteristics of the two groups regarding age, time of last menstruation, number of children, occupation, or number of pregnancies (Tab. 1).

The total mean (SD) scores of the MRS in the Aphrodit group were $21.93 \pm 3.83$ before intervention and $13.11 \pm 2.91$ after intervention. The placebo group's initial total menopausal symptom score was $22.13 \pm 3.36$; the score after using the placebo was $22.13 \pm 3.38$. There was a significant difference in the Aphrodit group before and after intervention ( $p=0.01$ ) (Tab. 2); there was no significant difference in the placebo group before and after intervention ( $p=1.0$ ) (Tab. 3). T test analysis showed that there was a significant difference between the two groups after intervention $(p=0.006)$ (Tab. 4).

\section{Discussion}

The purpose of this study was to determine whether a botanical supplement known as Aphrodit could assist in reducing symptoms of menopause. Mazora et al. (2010) showed that the consumption of Tribulus terrestris fruit was effective on the sexual performance of women [21]. In addition, Low observed in the USA that saffron supplements led to improvements in hot flushes and other menopausal symptoms [26]. The present study replicates these findings. The group treated with

Tab. 1. Demographic characteristics

\begin{tabular}{lccc}
\hline Characteristics & Afrodit & Placebo & The results of statistical tests for homogeneity \\
\hline Age & $55.3 \pm 53.6$ & $54.2 \pm 3.31$ & $t=0.7 ; \mathrm{df}=61 ; p=0.54$ \\
\hline Menopause age & $45.3 \pm 2.3$ & $48 \pm 1.9$ & $t=1.53 ; \mathrm{df}=46 ; p=0.15$ \\
\hline Number of children & $2.1 \pm 3.4$ & $3.6 \pm 1.7$ & $t=0.54 ; \mathrm{df}=61 ; p=0.58$ \\
\hline Number of pregnancies & $3 \pm 4.1$ & $2.1 \pm 4.8$ & $t=-1.47 ; \mathrm{df}=-98 ; p=-0.15$ \\
\hline Occupation status & Housewife (80\%) & Housewife (81\%) & Fisher Test $p=0.07$ \\
\hline
\end{tabular}

Tab. 2. Frequency of menopausal symptoms before and after the intervention in the Aphrodit group

\begin{tabular}{lccc}
\hline \multirow{2}{*}{ Menopausal symptoms } & Before & After & $\begin{array}{c}\text { Paired } t \text {-test } \\
\text { analysis }\end{array}$ \\
\cline { 2 - 4 } Physical & Mean \pm SD & Mean \pm SD & $t=1.98 ; \mathrm{df}=27 ; p=0.0001$ \\
\hline Mental & $9.31 \pm 1.75$ & $4.54 \pm 1.52$ & $t=2.11 ; \mathrm{df}=28 ; p=0.003$ \\
\hline Genitourinary & $9.31 \pm 2.30$ & $5.54 \pm 1.79$ & $t=1 ; \mathrm{df}=28 ; p=0.3$ \\
\hline Total & $3.31 \pm 1.49$ & $3.04 \pm 1.31$ & $t=1 ; \mathrm{df}=25 ; p=0.01$ \\
\hline
\end{tabular}

Tab. 3. Frequency of menopausal symptoms before and after the intervention in the placebo group

\begin{tabular}{lccc}
\hline Menopausal symptoms & Before & After & $\begin{array}{c}\text { Paired } t \text {-test } \\
\text { analysis }\end{array}$ \\
\cline { 2 - 4 } Physical & Mean \pm SD & Mean \pm SD & $t=8.52 ; \mathrm{df}=28 ; p=0.08$ \\
\hline Mental & $9.33 \pm 1.76$ & $9.27 \pm 1.96$ & $t=10.06 ; \mathrm{df}=28 ; p=0.3$ \\
\hline Genitourinary & $9.17 \pm 2.15$ & $9.03 \pm 2.07$ & $t=5.1 ; \mathrm{df}=25 ; p=0.8$ \\
\hline Total & $3.62 \pm 1.92$ & $3.83 \pm 2.01$ & $t=0.00 ; \mathrm{df}=29 ; p=1$ \\
\hline
\end{tabular}

Tab. 4. Comparison of menopausal symptoms after the intervention between the two groups

\begin{tabular}{lccc}
\hline $\begin{array}{l}\text { Group } \\
\text { Menopausal symptoms }\end{array}$ & Aphrodit & Placebo & $\begin{array}{c}\text { Independent } t \text {-test } \\
\text { analysis }\end{array}$ \\
\cline { 2 - 4 } Physical & Mean \pm SD & Mean \pm SD & $t=1.31 ; \mathrm{df}=98 ; p=0.0001$ \\
\hline Mental & $4.54 \pm 1.52$ & $9.27 \pm 1.96$ & $t=0.63 ; \mathrm{df}=98 ; p=0.02$ \\
\hline Genitourinary & $5.54 \pm 1.79$ & $9.03 \pm 2.07$ & $t=9.3 ; \mathrm{df}=98 ; p=0.1$ \\
\hline Total & $3.04 \pm 1.31$ & $3.83 \pm 2.01$ & $t=1.9 ; \mathrm{df}=98 ; p=0.006$ \\
\hline
\end{tabular}


Aphrodit in this study exhibited a significant improvement in menopausal symptoms, which might suggest that Aphrodit is tolerated better than many pharmaceutical tranquilisers currently being prescribed for this client group [25].

A previous study reported that Tribulus terrestris increased testosterone levels and improved sexual function in post-menopausal women [28]. However, in the present research, the Aphrodit supplement was ineffective in improving the genitourinary symptoms of menopausal women $(p=0.3)$.

On the other hand, for women who need relief for mild vasomotor symptoms, NAMS (2004) recommends considering lifestyle changes first, either alone or combined with a non-prescription remedy such as dietary isoflavones, black cohosh, or vitamin E. Other herbal supplements such as Aphrodite are not recommended [29].

It should be mentioned that the present study is limited by its small sample size, and the results cannot be generalised to a wider population. In addition, the study assessed only short-term effects; long-term effects were not tested in this study. These limitations should be considered in further studies.

\section{Conclusions}

Aphrodite improves the symptoms of menopause in postmenopausal women, and the findings of this study support the effectiveness of Aphrodite in the clinical management of menopausal symptoms. In addition, the absence of negative side effects, which are commonly seen with prescribed hypnotics, suggests that traditional herbal supplements might be a suitable alternative in the treatment of menopausal symptoms.

\section{Acknowledgments}

We would like to thank the Research Chancellor of Iran University Medical Sciences for the support and grants for this work. We are very grateful to the participants in this study for making this research possible. It should be noted that this study has been registered in the Iranian Registry of Clinical Trials (Code: IRCT201107122172N11).

\section{Disclosure}

Authors report no conflict of interests.

\section{References}

1. The North American Menopause Society (NAMS). Confirming menopause, 2010. Available at: http://www.menopause.org/MF200901two_ menopausestatus.aspx.

2. Beck W. Obstetrics and Gynecology. National medical series for independent study. Harwal Publishing, Philadelphia 1993; 359-360.
3. Taavoni S, Ekbatani N, Kashaniyan M, Haghani H. Effect of valerian on sleep quality in postmenopausal women: a randomized placebo-controlled clinical trial. Menopause 2011; 18: 951e5.

4. Bennett R, Brown L. Myles Textbook for Midwives. Churchill Livingstone, Edinburgh 1996; 37.

5. World Health Organization (WHO) Scientific Group. Research on the menopause in the 1990s. Geneva, Switzerland: World Health Organization; 1996. WHO Technical Report Series, No. 866.

6. Nelson HD. Menopause. Lancet 2008; 371: 760-770.

7. Bromberger JT, Matthews KA, Schott LL, et al. Depressive symptoms during the menopausal transition: the Study of Women's Health Across the Nation (SWAN). J Affect Disord 2007; 103: 267-272.

8. Speroff L, Fritz MA. Clinical Gynecologic Endocrinology and infertility. Lippincott Williams \& Wilkins Publisher 2005

9. Taavoni S, Nazem Ekbatani N, Haghani H. Valerian/lemon balm use for sleep disorders during menopause. Complement Ther Clin Pract 2013; 19 193-196.

10. Ohayon MM. Epidemiology of insomnia: what we know and what we still need to learn. Sleep Med Rev 2002; 6: 97-111.

11. Boulton A. Hormone therapy may protect against Alzheimer's disease. BMJ 1996; 313: 442.

12. Paganini HA. The risks and benefits of estrogen replacement therapy: leisure world. Int J Fertil Menopausal Stud 1995; 40: 54-62.

13. Evans ML, Pritts E, Vittinghoff E, et al. Management of postmenopausal hot flushes with venlafaxine hydrochloride: a randomized, controlled trial. Obstet Gynecol 2005; 105: 161-166.

14. Goolsby MJ. Management of menopause. J Am Acad Nurse Pract 2001; 13:147-150.

15. Taavoni S, Unesie Kafshgiri M, Shahpooryan F, Mahmoudie M. Hormone replacement therapy: postmenopausal sex life and attitudes towards sex. Psychogeriatrics 2005; 5: 9-14.

16. Rossouw JE, Anderson GL, Prentice RL, et al.; Writing Group for the Women's Health Initiative Investigators. Risks and benefits of estrogen plus progestin in healthy postmenopausal women: principle results from the women's health initiative randomized controlled trial. JAMA 2002; 288: 321-332.

17. Miller KJ, Conney JC, Rasgon NL, et al. Mood symptoms and cognitive performance in women estrogen users and non-users and men. J Am Geriatr Soc 2002; 50: 1826-1830.

18. Beral V; Million Women Study Collaborators. Breast cancer and hormone replacement therapy in the million women study. Lancet 2003; 362: 419 427

19. Keenan NL, Mark S, Fugh-Berman A, et al. Severity of menopausal symptoms and use of both conventional and complementary/alternative therapies. Menopause 2003; 10: 507-515.

20. 2003 National Sleep Disorders Research Plan. Sleep 2003; 26: 253-257.

21. Mazaro-Costa R, Andersen ML, Hachul H, Tufik S. Medicinal plants as alternative treatments for female sexual dysfunction: utopian vision or possible treatment in climacteric women? J Sex Med. 2010; 7: 3695-3714.

22. Akhondzadeh Basti A, Moshiri E, Noorbala AA, et al. Comparison of petal of Crocus sativus $L$ and fluoxetine in the treatment of depressed outpatients: a pilot double-blind randomized trial. Prog Neuropsychopharmacol Bio Psychiatry 2007; 31: 439-442.

23. Taibi DM, Vitiello MV, Barsness S, et al. A randomized clinical trial of valerian fails to improve self-reported, polysomnographic, and actigraphic sleep in older women with insomnia. Sleep Med 2009; 10: 319-328.

24. Huntley AL, Ernst E. A systematic review of herbal medicinal products for the treatment of menopausal symptoms. Menopause 2003; 10: 465-476.

25. Taavoni S, Nazem Ekbatani N, Haghani H. Effect of Afrodit on sexual satisfaction in menopausal women. Arak Medical University Journal 2014; 17 10-18.

26. Low Dog T. Menopause: a review of botanical dietary supplements. Am J Med 2005; 118 Suppl 12B: 98-108.

27. Darsareh F, Taavoni S, Joolaee S, Haghani H. Effect of aromatherapy massage on menopausal symptoms: a randomized placebo-controlled clinical trial. Menopause 2012; 19: 995-999.

28. Akhtari E, Raisi F, Keshavarz M, et al. Tribulus terrestris for treatment of sexual dysfunction in women: randomized double-blind placebo - controlled study. Daru 2014; 22: 40

29. North American Menopause Society. Treatment of menopause-associated vasomotor symptoms: position statement of The North American Menopause Society. Menopause 2004; 11: 11-33. 